\title{
Ecological constraints and trait conservatism drive functional and phylogenetic structure of amphibians larvae assemblages in the Atlantic Forest
}

Thiago Augusto Leão-Pires ( $\nabla$ leaopires.ta@gmail.com )

Universidade Estadual de Campinas

Amom Mendes Luis

Universidade Estadual de Campinas

Ricardo Jannini Sawaya

Universidade Federal do ABC

\section{Research Article}

Keywords: Ecophylogenetics, Functional diversity, Phylogenetic diversity, Tadpoles, Environmental control, Community ecology, Atlantic Forest

Posted Date: December 13th, 2021

DOI: https://doi.org/10.21203/rs.3.rs-1160051/v1

License: (c) (1) This work is licensed under a Creative Commons Attribution 4.0 International License.

Read Full License 


\section{Abstract}

Investigate how ecological and/or evolutionary factors could affect the structure of ecological communities is a central demand in ecology. In order to better understand that we assessed phylogenetic and functional structure of 33 tadpole communities in the Atlantic Forest coastal plains of Southeastern Brazil. We tested the assumption that phylogenetic conservatism drive tadpole traits. We identified 32 communities with positive values of phylogenetic structure, with 18 of those being significantly clustered. Twelve of 33 communities showed aggregated functional structure. Trait diversity was skewed towards the root, indicating phylogenetic trait conservatism and evolutionary factors as important drivers of tadpoles community structure. Six out of 11 environmental variables were selected in the best explanatory model of phylogenetic structure. Water conductivity, external and internal diversity of vegetation structure, canopy cover, and dissolved oxygen were negatively related with phylogenetic clustering, whereas presence of potential fish predators was positively related. Four of those environmental variables and area were also included in the best explanatory model of functional structure. All variables represent factors related to performance, survivorship, and distribution of anuran communities. From the 12 functionally structured communities, 10 were also phylogenetically structured. Thus, environmental factors may be acting as filters, interacting with phylogenetically conserved species traits, and driving linage occurrence in tadpole communities. Our study provides evidence that phylogenetic and functional structure in vertebrates are a result of interacting ecological and evolutionary agents, resulting in structured anuran assemblages.

\section{Introduction}

Communities structure are the expression of assembles rules. A crucial demand to ecologists is to disentangle the roles of contemporary and historical factors and their interactions as key determinants of community structure ${ }^{1-4}$. In the last decades, there has been an increased attention on the importance phylogenetic information to enhance our understanding of community structure ${ }^{3,4-8}$. The complex relationship between these intertwined factors makes understanding the processes driving the functional structure of ecological communities a major scientific challenge ${ }^{9-11}$. Therefore, it is interesting to integrate different approaches in order to expand our comprehension of the underlying processes originating and maintaining assemblages, including niche-based and evolutionary processes. Assessing phylogenetic structure of ecological communities gives us insights on evolutionary (e.g. natural selection) and ecological (e.g. competitive exclusion) mechanisms and processes, which can determine or influence community structure ${ }^{3,8,12-15}$. Additionally, functional structure of communities can reveal potential ecological mechanisms of community assemblage, as this structure is potentially the interaction of species functional traits and their habitats $4,9,16,17$.

Phylogenetic structure of ecological communities can be assessed by quantifying phylogenetic distances among species in a given assemblage and comparing the observed distances to null models ${ }^{3}$. If the observed phylogenetic mean distance is higher or lower than expected by null scenarios, one can state 
that there is a significant structure in that assemblage. The Mean Pairwise Distance (MPD) is a standardized metric of mean pairwise phylogenetic distance of taxa in a sample, which quantifies the phylogenetic clustering (positive values) or overdispersion (negative values) of taxa in a particular community ${ }^{3,18}$. This metric and its relationship with ecological variables has been used in numerous studies and is considered as the first step to uncover ecological (i.e., competitions or environmental filtering) and evolutionary mechanisms (i.e., in situ speciation or character displacement) driving phylogenetic structure of communities ${ }^{14,19-22}$

It has been suggested that environmental variables can act as ecological filters, for instance, constraining the assemblage of communities, i.e., progressively selecting species better adapted to local conditions from the regional pool, so, if species traits associated to these variables are phylogenetically conserved, it could lead to a phylogenetically clustered structure community ${ }^{3}$. However, interspecific competition could also be a main process leading to a clustered phylogenetic pattern, for instance, if closely related species have ecological differences that confer competitive advantage to one species in relation to another ${ }^{18}$. Thus, to correctly investigate drivers of assemblage structure, we should not just infer the processes from patterns of phylogenetic structure but evaluate the relationships among species traits and their environment.

Amphibians occurrences are affected by environmental variables such as canopy cover, that could indirectly affect the performance and occurrence of anurans in ponds ${ }^{23-25}$. The Vegetation heterogeneity of ponds is another important determinant of anuran reproduction or promotes micro-spatial heterogeneity, increasing the availability of sites for foraging and for seeking refuge from predators ${ }^{26-29}$. And finally, physico-chemical parameters of water, including $\mathrm{pH}$ and dissolved oxygen are known to directly and indirectly influence several aspects of anuran biology, including some species amphibians tadpole development and survival, consequently affecting occurrence of species in ponds ${ }^{30-36}$.

This well-established relationship between environmental variables and amphibians is commonly studied via ecomorphological traits or attributes describing behavioral and/or morphological characters ${ }^{37,38}$. These characters are believed to result from ecological and evolutionary processes acting on species 39,40. An interesting and innovative approach to evaluate the association between functional traits and environment is to investigate the functional structure of communities (e.g. ${ }^{41-43}$ ). In this context, both traits and their interactions provide information about how communities respond to environmental conditions ${ }^{44}$. This can be achieved by measuring the mean pairwise functional distance between communities (hereafter namely MPD-functional), derived directly from functional diversity (FD, ${ }^{37,38}$ ). Similar to MPD, MPD-functional positive values indicate a more functionally diverse community, expected to show a high degree of niche partitioning among species. On the other hand, negative values of MPDfunctional indicate niche overlap, with species expected to be more functionally similar to each other. However, in order to improve our understanding and correctly interpret phylogenetic and functional structure of communities, the relationships of phylogenetic relatedness and ecological traits of species, or Phylogenetic Niche Conservatism (PNC) should also be verified ${ }^{40}$. This can be accomplished by testing 
the tendency for closely related species to be more phenotypically similar each other when compared to species drawn randomly from species pool, and by quantifying their phylogenetic signal ${ }^{40,45-47}$.

Although there has been an impressive increase in studies of phylogenetic ecology and community structure in the last decades, this approach has only been applied to a few taxonomic groups $3,7,18$. Also, methods that combine both functional traits and phylogenetic data can be even more powerful to unravel assembly rules of communities ${ }^{48-50}$. Anurans are one of the most diversified groups of vertebrates in the Neotropical region ${ }^{51}$, particularly in Brazil $\left(\mathrm{N}=1080\right.$ species; $\left.{ }^{52}\right)$, with several recent phylogenetic hypotheses available ${ }^{53-58}$. Anurans are an interesting model to investigate the mechanisms related to the phylogenetic structure of communities. Manly due to their complex life cycle, permeable skin, limited dispersal, anurans are highly sensitive to ecological and evolutionary processes, such as environmental control and speciation $28,29,59-61$.

Specifically, tadpoles may occur in a great range of aquatic habitats, from depression in trunks of tree (e.g., fitolimns) to lakes or streams, among others. Thus, tadpoles are exposed to many types of biotic and abiotic factors ${ }^{62}$. Also, the occurrence of aquatic habitats by tadpoles also could be determined by historical constraints imposed by colonization and phylogeny of species ${ }^{63,64}$. Therefore, Pond communities provide a good opportunity to study assembly rules, because they have easily recognizable limits, similarly to islands, where assembly rules have historically been studied ${ }^{65}$.

Our aims in this study are threefold. We first evaluate the phylogenetic and functional structure of anuran tadpoles assemblages in Atlantic Forest coastal plains of southeastern Brazil. We then test the assumption of phylogenetic conservatism to improve our understanding to better understand the phylogenetic and functional structure of tadpoles. And finally, we assess the relative importance of environmental predictors to phylogenetic and functional structures. We expect that: (i) anuran tadpole communities show a clustered phylogenetic and functional structure mainly because (ii) tadpoles exhibit phylogenetically conserved traits; and (iii) the phylogenetic and functional structure of assemblages are strongly related to environmental predictors such as vegetation structure and physico-chemistry parameter of ponds, which in turn affect anuran biology and ecology.

\section{Materials And Methods}

\section{Biological surveys}

The study was conducted in coastal plains of São Paulo state, Southeastern, Brazil, between October 2011 and April 2012. The region comprehends approximately $550 \mathrm{~km}$ of coastal plains of Atlantic Forest constrained by Precambrian basements of the Serra do Mar mountain range in south and north and divided by Precambrian formations ${ }^{67}$. Coastal plains in this region are limited by Cenozoic escarpments ${ }^{66,67}$. 
We sampled tadpoles and potential fish predators from 33 ponds in the study area (Fig. 1). For this study, each pond was considered as an ecological community. The ponds were selected in order to maximize the diversity of physical and vegetational structure, for example, from ponds in open areas to small puddles in forested areas, but all in coastal areas of the Atlantic Forest (more details abouts sampled ponds, see Environmental data section and Supplementary Table S1). Each pond was sampled three times, from October 2011 to March 2012, at the beginning, middle and end of the reproductive season of the Atlantic forest amphibians. Animals were collected in suitable microhabitats for tadpoles and fishes. Specimens were identified to species level in laboratory and deposited in the "Coleção Científica de Anfíbios" - Universidade Estadual Paulista "Júlio de Mesquita Filho", São José do Rio Preto, São Paulo, Brazil. The collection and surveys protocol/ experimental protocol were approved and provided by the animal ethical committee Instituto Chico Mendes de Conservação da Biodiversidade (ICMBio) (\#315541). All methods were performed in accordance with the relevant guidelines and regulations.

The tadpole abundance in ponds is commonly related to species reproductive modes and strategies ${ }^{68,69}$. We then used a log transformed abundance matrix, since higher logarithmic bases give less weight to quantities than to presences ${ }^{70}$.

\section{Environmental data - sampling and processing}

We measured the following local habitat variables: pond area, canopy cover, diversity of internal and external vegetation structure, presence of potential predators (fish), $\mathrm{pH}$, water temperature, water conductivity, dissolved oxygen and water depth (see Supplementary Table S1 for further details). We transformed continuous variables (area, water depth, water temperature, water conductivity and dissolved oxygen) by Gower standardization as recommended by ${ }^{71}$. Gower's coefficient could be defined as the mean of squared distances between samples ${ }^{72}$, in this case, environmental continuous variables. Thus, all numerical variables had equal weight in analyses. Variables were not correlated to each other (Pearson correlation, $r<0.60$ ), and were all included in subsequent models. Pearson correlation coefficient are quite arbitrary and tend to depends on the variables analyzed, but as a rule of thumb, we considered an absolute value of $r<0.60$ as a weak to modest correlation between environmental variables.

\section{Phylogenetic data - sampling and processing}

In order to calculate MPD and to test phylogenetic signal, we built a pruned tree from our regional species pool, based on a phylogenetic hypothesis from ${ }^{73}$ (Fig. 2). Our regional pool was represented by all species recorded in the Serra do Mar coastal forests $(N=232)$ as registered in ${ }^{74}$.

\section{Trait data - sampling and processing}

We tested the premise of trait phylogenetic conservatism calculating the mean pairwise functional distance (MPD-f). We measured well-known ecomorphological attributes described by nine morphological characters (see Appendices Fig. A1 for further details) related to habitat use of tadpoles (see ${ }^{68}$ ). It was 
considered tadpoles with stages ranging from 33 to $39\left(\right.$ sensu $\left.^{75}\right)\left(\right.$ see $\left.^{76}\right)$. The ecomorphological attributes were: relative caudal height $(\mathrm{RCH}=(\mathrm{HCM}+\mathrm{HDF}+\mathrm{HVF}) / \mathrm{BH})$; body compression $(\mathrm{BC}=$ $B H / B T L)$, relative width of caudal musculature $(R W C M=H C M / M C W)$, relative caudal length $(R C L=(B T L-$ $\mathrm{BL}) / \mathrm{BL})$, and relative spiracle size $(\mathrm{RSP}=\mathrm{SH} / \mathrm{BH})$. The following categorical attributes were also included:

body shape (BS), position of oral opening (OR), eye position (EP), number of denticle rows (NDR), spiracle position (SP), and presence or absence of flagellum (FP) (for more details about the abbreviations and the nomenclature, see Supplementary Table S1).

Traits were selected based on strong ecological associations and biological features of tadpoles, including habitat use and foraging behaviour, which may influence ecosystem functions and specific defence against predators, such as position of the eyes (morphological trait), position on the water column (habitat use) and predation risk (ecological association), but for more details about the relationship between traits and habitats variables, see $^{62,77,78}$.

The selected ecomorphological attributes (numerical and categorical) were used to construct a pairwise distance matrix of species traits based on Gower dissimilarity for mixed variables ${ }^{79}$.

\section{Data Analysis}

\section{Phylogenetic signal}

We employed the tips/root skewness test for Phylogenetic Niche Conservatism ${ }^{46}$. This test maps trait diversity across the phylogenetic tree. It is compatible with the global trait distance among species proposed by ${ }^{71}$, which handles both categorical and quantitative traits. It can estimate whether trait diversity is skewed to the root, or if closely related species tend to have more similar trait values (e.g., due to phylogenetic conservatism) or if trait diversity is skewed to tips, indicating that closely related species tend to have highly dissimilar trait values (e.g., due to convergent trait evolution). This metric requires three steps as follows: a test to assess if trait diversity is concentrated at a single node, the single-node skewness test; another test to assess if trait diversity values are evenly distributed across nodes of the functional dendrogram, the few-nodes skewness test which complements the "single-node skewness test", used to assess whether only a few nodes have higher contributions to trait diversity; and finally the tips/root skewness test, to test if trait diversity is more concentrated near the root or the tips of the functional dendrogram. In order to test these assumptions, we compared simulated trait diversity values to observed values via permutations test, which consist in permuting the species across the tips of the phylogenetic tree ${ }^{46}$. We then calculated diversity of traits based on Rao quadratic entropy ${ }^{46,80}$.

\section{Phylogenetic and functional structure analysis}

We evaluate phylogenetic structure of tadpoles by Mean Pairwise Phylogenetic Distance (MPD), following the formula: 


$$
M P D=\frac{\left(m n\left(X_{o b s}\right)-m n X(n)\right)}{s d X(n)}
$$

where $X_{o b s}$ is the phylogenetic distance between two taxa (the sum of branch lengths among the two taxa) from the phylogenetic pool; $m n\left(X_{o b s}\right)$ is the mean value of all possible pairs of $n$ taxa from the phylogeny; $m n X(n)$ is the mean for $n$ taxa randomly distributed on the phylogeny; and $s d X(n)$ are standard deviation expected for $n$ taxa randomly distributed on the phylogeny.

The MPD is a standardized measure of PD, based on Phylogenetic Diversity (PD), developed by ${ }^{3}$, but it has his roots on Faith's $\mathrm{PD}^{81}$. The $\mathrm{MPD}_{\text {obs }}\left(X_{o b s}\right)$ values of each community were compared to permutations of the community matrix (MPD null) randomized from the regional pool with equal probability ${ }^{82}$. This metric test whether communities are assembled by species which are more (i.e., clustered) or less (i.e., overdispersed) phylogenetically related than expected by chance ${ }^{3,83}$.

To assess the functional structure of tadpoles, we implemented an approach analogous to the MPD, by Mean pairwise Functional Distance (MPD-f) ${ }^{84}$. As in MPD, we calculated the standardized size effect, but using the functional diversity (FD) to generate the MPD-functional and thus its standardized size effect values $^{82}$. The FD was calculated based on sum of branch lengths of the functional dendrogram necessary to connect all the species present in a local community, as follows:

$$
F D_{Q}=\sum_{i=1}^{s-1} \sum_{j=i+1}^{n} d_{i j} p_{i} p_{i}
$$

$F D_{Q}$ expresses the average functional difference between any two randomly selected individuals; $d_{i j}$ is the difference between the $i$ and $j$ species $\left(d_{i j}=d_{j i}\right.$ and $\left.d_{i i}=0\right)$, and $p$ is the relative abundance vector for each species $i\left(\right.$ e.g. $\left.{ }^{79,85}\right)$. In order to generate the functional dendrogram, we first calculated a distance matrix based on the functional traits. As we had qualitative and quantitative traits, we used a generalization of Gower distance ${ }^{79}$ to the treatment of mixed data and then implemented an UPGMA (Unweighted Pair Group Method using arithmetic Averages) hierarchical clustering to create the functional dendrogram ${ }^{79,86}$. The following steps are equivalent to MPD exposed above, comparing the values of MPD $-f_{\text {obs }}$ to simulated permutations of the community matrix (MPD-f $f_{\text {null }}$ ) randomized from the phylogenetic pool with equal probability ${ }^{83}$. Analogously, this metric can also test whether species of a community are more or less functionally similar than expected by chance, generating the MPD-f $83,84,87$. We then used only communities with significantly MPD-f values for further analysis.

Spatial dependence between samples is commonly observed in nature and it can cause noise and bias to statistical modeling if not considered ${ }^{88}$. This phenomenon is called spatial autocorrelation, that is, values of variables sampled in neighbor sites are not independent of each other, violating the assumption of independence between samples in statistical models ${ }^{88}$. Moreover, if there is spatial autocorrelation in the 
models, it will also lead to spatial autocorrelation in residuals ${ }^{89}$. Thus, in order to avoid spatial bias in models, we performed a Moran / test, which describes spatial autocorrelation in the data applied to residuals of a regression between MPD and MPD-f significant values and environmental variables. In our case, we did not find a significant spatial autocorrelation in the residuals of the regression model (MPDphylogenetic $=$ Moran I $=-0.758 ; p=0.50 ;$ MPD-functional $=$ Moran I= 0.937, $p=0.46$ ).

We also selected the best predictive environmental model for each community structure metric using a Stepwise Model Selection based on corrected Akaike information criteria $\left(\mathrm{AIC}_{\mathrm{c}}\right)^{90,91}$. We employed a Generalized Linear Models approach (GLM), expressed by the adjusted $R^{2}$ statistic $\left(R^{2}{ }_{a d j}{ }^{92}\right)$, to assess the variance of MPD and MPD-f that are potentially explained by each environmental predictor. We also used the Hierarchical Partitioning ${ }^{93}$ to evaluate the independent and joint contributions of each environmental predictor ${ }^{94,95}$. Additionality, a Redundancy Analysis (RDA) was conducted in order to explore the relative importance of environmental heterogeneity, functional guilds and phylogenetic clades $^{79}$.

\section{Results}

We recorded 25 anuran species ( $\mathrm{N}=20.762$ individuals) belonging to four families (Hylidae, Leptodactylidae, Microhylidae, Bufonidae) and 12 genera (Fig. 2) in all 33 communities (ponds). The Rao's diversity coefficient was 0.135 at coastal plains of Atlantic Forest. Tadpole trait diversity was concentrated in a few nodes of the phylogeny (Fig. 3; single-node skewness test, observed value $=0.190$, $P<0.004$; few nodes skewness test, observed value $=0.307, P<0.001)$. The tips skewness test revealed that trait diversity is concentrated near the root of the phylogeny (Fig. 3, observed value $=0.420, P<$ 0.001). As the trait diversity was concentrated in few nodes and close to the root of the phylogeny, we confirm that trait diversity of anuran tadpoles from Atlantic Forest coastal plains are phylogenetically conserved.

MPD-phylogenetic values of the tadpole communities ranged from -2.18 to 0.57 (mean $=-1.06 \pm 0.51$ ). Among the 33 sampled tadpole communities, 18 (approximately 55\%) showed a phylogenetic clustered structure, with species more closely related than expected by chance. The 14 remaining communities had non-significant negative MPD values.

The MPD-functional values of tadpole communities ranged from -4.38 to 1.45 (mean= $-2.07 \pm 0.89$ ). Among the 33 tadpole communities (ponds) sampled, 12 (approximately $37 \%$ ) showed an aggregated functional structure with species more functionally similar than expected by chance. The 21 remaining communities had non-significant negative MPD values. Notably, of the 12 communities with aggregated functional structure, 10 also showed a clustered phylogenetic structure.

The Redundancy Analysis (RDA) revealed that variance of the relationship between phylogenetic clades and environment explained by the first two canonical axes was $87.4 \%$ (53.9\% for axis 1 and $33.5 \%$ for 
axis 2, respectively, see Fig. 4a). The variance of functional guilds-environment relation was $83.0 \%$ (55.2\% for axis 1 and $27.8 \%$ for axis 2, respectively, see Fig. $4 b$ ).

The overall model with six environmental variables explained $58 \%\left(R^{2} a d j=0.58\right)$ of total variance of phylogenetic structure. The best environmental fitting the MPD-phylogenetic included six variables: presence of potential fish predators, internal and external vegetation diversity, canopy cover, dissolved oxygen and water conductivity (Table 1a). The most important environmental predictors in GLM model were presence of potential fish predators (predator), followed by water conductivity, external vegetation structure diversity (external pond vegetation), canopy cover, internal vegetation structure diversity (internal pond vegetation) and oxygen dissolved (Table 1a, Fig. 5a). Predator presence was positively correlated to MPD values, whereas water conductivity, canopy cover, internal vegetation, external vegetation and oxygen dissolved were negatively associated (Fig. 5a).

On the other hand, the best environmental model to MPD-f selected trough stepwise model selection based on AICc included five variables: external vegetation diversity, canopy cover, area, dissolved oxygen and presence of potential fish predators. The overall model with these five variables explained $41 \%$ $\left(R^{2} a d j=0.41\right)$ of total variance of functional structure. The most significant environmental variables in GLM model were external vegetation, followed by canopy cover, dissolved oxygen and predator (Table $1 \mathrm{~b}$, Fig. 5b). Finally, external vegetation, canopy, area and dissolved oxygen were negatively associated with the MPD-functional values, whereas predator was positively correlated (Fig. 5b).

\section{Discussion}

Our general aim in this study was to investigate the phylogenetic and functional structure of tadpole communities (ponds) from coastal plains in southeastern Brazil and what ecological and evolutionary processes (such as ecological filtering or trait conservatism) potentially affect their structure. Earlier studies on plant communities argue that when taxonomic levels increase, phylogenetic structure shifts from overdispersion to clustering ${ }^{13}$. Recent studies found that phylogenetic clustering tends to increase with spatial extent from local to landscape scales, probably due to higher environmental variation at broad spatial scales ${ }^{13,95,96}$. In this scenario, assemblages would be driven by niche conservatism in more regional scales, while species interactions would determine community structure at local scales ${ }^{13}$. However, according to our predictions, we found a clustered phylogenetic structure in most sampled ponds (18 out of 33 communities). This pattern was also already found in Pantanal at regional and local scales, although the processes underlying remains unclear at local scales ${ }^{97}$. In fact, clustered phylogenetic structure has been considered fundamental if not the dominant pattern in recent studies of phylogenetic structure of vertebrate assemblages (e.g. 5,7,14,98). We then argue the possibility of, contrary to plant communities, clustered phylogenetic structure as an important pattern for vertebrates, even at local scales.

Our results also showed that 12 communities were composed by species more functionally similar than expected by chance, and 10 of these communities also displayed a clustered phylogenetic structure. 
Functional structure related to phylogenetic structure was also found in other vertebrate groups, including birds $^{5,99,100}$, bats ${ }^{101}$ and fishes ${ }^{102,103}$. These findings point out to a likely general pattern in vertebrates, where phylogenetic and functional structures are interconnected at some level, as phylogeny could inform about functional structure or could be employed as a possible proxy of each other, even if they could not be considered directly interchangeable. This is because part of the functional structure is not related to phylogenetic structure, which may be the outcome of ecological or stochastic processes. On the other hand, phylogenic structure unrelated to functional structure could be a result of evolutionary processes such as genetic drift $^{40}$.

We found that the two best environmental models of MPD and MPD-f included six and five environmental variables, respectively, indicating that species composition and abundance changes on clades and functional groups are related to environmental variables. The presence of potential fish predators was the most important variable and the only one positively related to clustered phylogenetic structure (MPD, Fig $5 a)$. On the other hand, this variable was less important but positively related to functional structure (MPD-f, Fig. 5b). The influence of predation on occurrence and co-occurrence of species has been well documented ${ }^{104}$. Predators can cause prey to modify their behavior, morphology, life history, and physiology in an attempt to reduce risks of predation ${ }^{105-109}$. Fish predators can negatively affect the development and growth of tadpoles, as well as select morphological changes. On the other hand, these effects on prey can be regarded as adaptive responses to the presence of predators ${ }^{108,110,111}$. Predation could also reduce interspecific prey competition, for instance, by reducing or eliminate entire populations of strong competitors, leaving an empty ecological niche space to competitively weaker species ${ }^{109,112}$.

Some studies reveal that aquatic predators selected prey characteristics in a non-random fashion ${ }^{111,113}$. We found an increase of potential predator presence associated to clustered phylogenetic structure. Thus, potential predators seem to be negatively associated with anuran species occurrence or even functional guilds of adhrent and macrophagous species (Fig. 4b). On the other hand, predators are apparently favoring the occurrence of species of Bufonidae (Fig. 4a). It could reflect specific defenses that many species of this family display, such as toxins present in the cutis and body fluids of several Bufonid species ${ }^{114}$.

Water conductivity was a significant explanatory predictor for taxonomical and functional beta diversity of anuran tadpoles ${ }^{115}$ and was the second most significant explanatory variable of phylogenetic structure (Fig. 5a). It is known that water conductivity can be a surrogate to food availability or productivity in a pond, as higher productivity provides more hydrogen ions, and thus a higher conductivity $^{116}$. The higher the productivity, the higher the availability and quality of food resources (periphyton) will be. In turn, high productivity will generate an increase of species performance in aquatic communities, a biological aspect commonly associated to certain species traits, such as those related to caudal and oral morphology of tadpoles $23,24,117-119$. Conductivity could be indicating a positive association of productivity to certain lineages as Microhylids (Fig. 4a) by these mechanisms. However, 
the same variable shows a negative relationship to Leptodactylids, even though such association remains to be further investigated.

We also found an important influence of external vegetation diversity to MPD, and this was the most important variable to MPD-f (Fig. 5b). This variable probably determines the availability of suitable sites for vocalization, amplexus, and oviposition for adults, interacting with species traits in ponds. Thus, external vegetation structure diversity of a pond is expected to be associated with distribution and reproduction of anurans, mainly for Hylidae $27,120-122$, but was more strongly associated with Leptodactylids than Hylids (Fig. 4a), which a result that still demands ecological interpretations. Canopy cover was the fourth most important explanatory variable of phylogenetic structure and the second more important of functional structure (Fig. 5a,b). In fact, canopy cover is claimed to indirectly drive species diversity, and the growth and development of tadpoles in aquatic habitats, because open-canopy ponds tend to have higher productivity, and as discussed here, ponds with higher productivity show higher resource availability and quality $23-25,119,123$. It is worth noting that canopy cover was already recovered as an important predictor of anuran functional and phylogenetic beta diversity ${ }^{115}$ and metacommunity structure $^{124}$. Also, there is evidence that canopy cover may be a significantly source of nutrients, acting as key predictor for tadpoles growth and development ${ }^{125}$. In our sampled ponds, this variable was positively associated to MDP, indicating that ponds with more closed canopies show phylogenetic clustering. Canopy cover seems to be segregating forest interior clades, such as Microhylids, from open area clades, as Hylids (Fig. 4a); and it is positively associated with adhrent and microphagous tadpoles, functional groups influenced by food accessibility, strongly affected by canopy cover (Fig. 4b) $64,65,126$.

Internal vegetation structure diversity was the fifth explanatory variable selected for MPD (Fig. 5a). This variable has been identified as important descriptor of functional, taxonomical and phylogenetic beta diversities ${ }^{115}$. This predictor is vital to anurans, as it provide suitable sites to vocalization, amplexus, oviposition, and even predator protection to adults and tadpoles $27,117-122,127$. Therefore, increased heterogeneity of overall vegetation structure on ponds, such as higher presence of shrubs and trees, may be favoring the presence of certain species, including treefrog members of Hylidae family. Hylids are the most representative family in our study region and they use mainly hanging vegetation as vocalization sites $^{27,69,128}$. This is mostly due to their adhesive disks on fingers, a key trait to anurans, allowing the exploration of three-dimensional habitat ${ }^{69}$. Given that, vegetation structure may affect the occurrence of this anuran clade. Higher vegetation diversity was then positively related to treefrogs, affected by vertical vegetation availability, and negatively related to toads (Bufonidae), that typically reproduce on the ground (Fig. $5 \mathrm{a} ;{ }^{69}$ ). Therefore, it suggests that external and internal vegetation structure may be affecting the phylogenetic structure of tadpole communities.

Dissolved oxygen in water (DO) was the sixth most important explanatory predictor of MPD, but the fourth more important to MPD-functional (Fig. $5 a$ and b). This physical parameter of water has a strong influence on tadpole species-specific performance and survivorship ${ }^{116,129-131}$. Thus, it could be affecting the presence of species of distinct lineages, such as Bufonids, which does not have functional lungs in 
early larval stages ${ }^{130}$. In our study, the DO was negative linked to Leptodactylid, Hylids and benthic tadpoles, but positive associated to Microhylid and Nektonic tadpoles (Fig. 4a, b). However, the impacts of long-term hypoxic conditions on growth and development of tadpoles are not yet well understood ${ }^{23}$.

Surface area was the third most important explanatory variable to the functional structure (Fig. 5b). Physical parameters of water bodies are known to influence the diversity and distribution of tadpoles, but in complex ways. The Island Biogeography theory (IBT) predicts that species richness increases with island size at a certain distance from a source of colonizers. However, stream volume (a variable strong related to surface area) was negatively and weakly associated to tadpoles richness ${ }^{132}$, the inverse of the prediction of IBT, if we consider water bodies as islands within land habitats as a matrix. But the increasing surface-area-to-volume ratio was also positively associated to fitness of Bufo americanus. Likewise, in coastal plains ponds, benthic tadpoles, such as Rhinella ornata were positive associated to area (Fig. 4b), but nektonic species, such as Scinax spp. were negative related to this variable.

In summary, our best predictors were mainly negatively related to MPD and MPD-f structure of tadpole communities, indicating that a decrease in values of these variables generally is associated to more clustered assemblages, both in functional and phylogenetic diversity. In other words, ponds with lower environmental complexity or heterogeneity show more closely related species than expected from random assemblages. Therefore, environmental variables are probably constraining community composition, by filtering tadpole lineages or functional guilds, and in association with the species phylogenetic conserved traits, generate an emergent clustered phylogenetic structure. In fact, these factors are acting particularly in some clades, limiting the occurrences of Microhylids and Bufonids, and favoring the occurrence of Hylids, and acting as assembly rules to tadpole communities. Our study provides an important step to further understand anuran community structure and their underlying assembly processes. Anurans assemblages are the outcome of interactions between ecological and evolutionary processes, such as environmental filters and phylogenetic trait conservatism.

\section{Declarations}

\section{Acknowledgements}

We thank specially Bruno Silva for field assistance. We also thank Denise Rossa-Feres, Mainara Jordani, Lilian S. O. de Melo and Luis Schiesari for great contribution in tadpole identification and Liam J. Revell for help in handling the anuran phylogenetic tree. Denise Rossa-Feres and Leandro Duarte kindly made very useful comments on earlier versions of the manuscript. Cristiano de $\mathrm{C}$. Nogueira made the linguistic correction and valuable suggestions in the manuscript. We thank CAPES for providing grants. This work was funded by FAPESP (procs. 2008/54472-2 and 2014/23677-9), Graduate Program in Ecology (UNICAMP), SISBIOTA Project: FAPESP (proc. 2010/52321-7), CNPq (procs. 304929/2015-8, 563075/2010-4 and 405447/2016-7. 
Author Contributions: TALP, AML and RJS originally formulated the idea, TALP and AML developed methods, TALP and AML conducted fieldwork, TALP performed statistical analyses, and TALP, AML and RJS wrote the manuscript. All authors reviewed the manuscript.

\section{Competing Interest statement}

The authors declare no competing interests.

\section{References}

1. Ricklefs RE. Community diversity: relative roles of local and regional processes. Science 235:167171. https://doi.org/10.1126/science.235.4785.167 (1987)

2. Ricklefs RE, Schluter, D. Species diversity in ecological communities: historical and geographical perspectives, $1^{\text {st }}$ edn.. University of Chicago Press, (Chicago, 1993).

3. Webb CO, Ackerly DD, Mcpeek MA, Donoghue MJ. Phylogenies and Community Ecology.Annu. Rev. Ecol. Syst. 33:475-505. https://doi.org/10.1146/annurev.ecolsys.33.010802.150448 (2002)

4. Webb $\mathrm{CO}$, Cannon $\mathrm{CH}$, Davies SJ. Ecological organization, biogeography, and the phylogenetic structure of tropical forest tree communities. In: Carson WP, Schnitzer SSA (Eds.) Tropical Forest Community Ecology. Blackwell, Oxford, pp 79-97 (2008)

5. Che X. et al. Phylogenetic and Functional Structure of Wintering Waterbird Communities Associated with Ecological Differences. Scientific reports 8: 1232. https://doi.org/10.1038/s41598-018-19686-3 (2018).

6. Mouquet N. Ecophylogenetics: advances and perspectives. Biological reviews 87(4):769 -785. https://doi.org/10.1111/j.1469-185X.2012.00224.x (2012).

7. Vamosi SM, Heard SB, Vamosi JC, Webb CO. Emerging patterns in the comparative analysis of phylogenetic community structure. Molecular Ecology, 18:572-92. https://doi.org/10.1111/j.1365294X.2008.04001. (2009).

8. Yan C, Xie Y, Li X, Holyoak M, Zhang Z Species co-occurrence and phylogenetic structure of terrestrial vertebrates at regional scales. Global ecology and biogeography, 25:455-463. (2016)

9. Mouillot D, Villéger S, Scherer-Lorenzen M, Mason NW. Functional structure of biological communities predicts ecosystem multifunctionality. PloS one, 6(3), e17476. https://doi.org/10.1371/journal.pone.0017476 (2011).

10. Velázquez E, Paine $C E$, May F, Wiegand T. Linking trait similarity to interspecific spatial associations in a moist tropical forest. Journal of vegetation science $26: 1068$ 1079. https://doi.org/10.1111/jvs.12313 (2015).

11. Villéger S, Miranda JR, Hernández DF, Mouillot D. Contrasting changes in taxonomic vs. functional diversity of tropical fish communities after habitat degradation. Ecological application 20(6): 15121522. https://doi.org/10.1890/09-1310.1 (2010). 
12. Cavender-Bares J, Ackerly DD, Baum DA, Bazzaz FA. Phylogenetic overdispersion in Floridian oak communities. Am. Nat. 163:823-43. https://doi.org/10.1086/386375 (2004).

13. Cavender-Bares J, Keen A, Miles B. Phylogenetic structure of Floridian plant communities depends on taxonomic and spatial scale. Ecology 87:109-122. https://doi.org/10.1890/0012-9658 (2006).

14. Graham $\mathrm{CH}$, Parra JL, Rahbek C, Mcguire JA. Phylogenetic structure in tropical hummingbird communities. Proc. Natl. Acad. Sci. U. S. A. 106 Suppl:1967319678. https://doi.org/10.1073/pnas.0901649106 (2009).

15. Willis CG. Phylogenetic community structure in Minnesota oak savanna is influenced by spatial extent and environmental variation. Ecography 3:565-577. https://doi.org/10.1111/j.16000587.2009.05975.x (2010).

16. Mouchet MA, Villéger S, Mason NW, Mouillot D. Functional diversity measures: an overview of their redundancy and their ability to discriminate community assembly rules. Functional Ecology, 24(4), 867-876. (2010).

17. Villéger S, Miranda JR, Hernández DF, Mouillot D. Contrasting changes in taxonomic vs. functional diversity of tropical fish communities after habitat degradation. Ecological Applications 20:15121522. https://doi.org/10.1890/09-1310.1 (2010)

18. Cavender-Bares J, Kozak KH, Fine PVA, Kembel SW. The merging of community ecology and phylogenetic biology. Ecol. Lett. 12:693-715. https://doi.org/10.1111/j.1461-0248.2009.01314.x (2009).

19. Cardillo M. Phylogenetic structure of mammal assemblages at large geographical scales: linking phylogenetic community ecology with macroecology. Philos. Trans. R. Soc. Lond. B. Biol. Sci. 366:2545-53. https://doi.org/10.1098/rstb.2011.0021 (2011).

20. Letcher SG. Phylogenetic structure of angiosperm communities during tropical forest succession. Proc. Biol. Sci. 277: p.97-104. (2010).

21. Swenson NG, et al. Phylogenetic and functional alpha and beta diversity in temperate and tropical tree communities. Ecology 93:S112-S125. https://doi.org/10.1890/11-0402.1 (2012).

22. Webb CO. Exploring the phylogenetic structure of ecological communities: an example for rain forest trees. Am. Nat. 156145-155. https://doi.org/10.1086/303378 (2000).

23. Skelly DK, Freidenburg LK, Kiesecker JM. Forest canopy and the performance of larval amphibians. Ecology 83:983-992. https://doi.org/10.1890/0012-9658(2002)083[0983:FCATPO]2.0.C0;2 (2002).

24. Skelly DK, Halverson MA, Freidenburg LK, Urban MC. Canopy closure and amphibian diversity in forested wetlands. Wetl. Ecol. Manag. 13:261-268. https://doi.org/10.1007/s11273-004-7520-y (2005).

25. Werner EE, Skelly DK, Relyea RA, Yurewicz KL. Amphibian species richness across environmental gradients. Oikos 116:697-1712. https://doi.org/10.1111/j.0030-1299.2007.15935.x (2007).

26. Moreira, LFB, Machado IF, Garcia TV, Maltchik L. Factors influencing anuran distribution in coastal dune wetlands in southern Brazil. J. Nat. Hist. 44: p.14931507. https://doi.org/10.1080/00222931003632690 (2010). 
27. Wassens S, Hall A, Osborne W, Watts RJ. Habitat characteristics predict occupancy patterns of the endangered amphibian Litoria raniformis in flow-regulated flood plain wetlands. Austral Ecol. 35:944-955. https://doi.org/10.1111/j.1442-9993.2010.02106.x (2010).

28. Silva FR, Gibbs JP, Rossa-Feres DC. Breeding Habitat and Landscape Correlates of Frog Diversity and Abundance in a Tropical Agricultural Landscape. Wetlands 31:10791087. https://doi.org/10.1007/s13157-011-0217-0 (2011).

29. Silva FR, Candeira CP, Rossa-Feres DC. Dependence of anuran diversity on environmental descriptors in farmland ponds. Biodivers. Conserv. 21:1411-1424. https://doi.org/10.1007/s10531-012-0252-z (2012)a.

30. Leuven R, Den Hartog C, Christians MMC, Heijligers WHC. Effects of water acidification on the distribution pattern and the reproductive success of amphibians. Experientia 42:495-503. (1986).

31. Warner SC, Dunson WA, Travis J. Interaction of $\mathrm{pH}$, density, and priority effects on the survivorship and growth of two species of hylid tadpoles. Oecologia 88:331339. https://doi.org/10.1007/BF00317575 (1991).

32. Warner SC, Travis J, Dunson WA. Effect of $\mathrm{pH}$ variation of interspecific competition between two species of hylid tadpoles. Ecology 74:183-194. https://doi.org/10.2307/1939513 (1993).

33. Pehek, EL. Competition, pH, and the ecology of larval Hyla andersonii. Ecology 76:17861793. https://doi.org/10.2307/1940710 (1995).

34. Moore MK, Townsend JR. The interaction of temperature, dissolved oxygen and predation pressure in an aquatic predator-prey system. Oikos 81:329-336. (1998).

35. Alford RA. Ecology: resource use, competition, and predation. Tadpoles Biol. anuran larvaep.240-278. (1999).

36. Ultsch GR. Bradford DF, Freda J. Physiology: Coping with the environment. In: McDiarmid, R.W. and Altig, R., Eds., Tadpoles: The Biology of Anuran Larvae, University of Chicago Press, Berkeley. (1999).

37. Petchey OL, Gaston KJ. Functional diversity (FD), species richness and community composition. Ecology Letters, 5:402-411. https://doi.org/10.1046/j.1461-0248.2002.00339.x (2002).

38. Petchey OL, Gaston KJ. Functional diversity: back to basics and looking forward. Ecology letters, 9:741-758. https://doi.org/10.1111/j.1461-0248.2006.00924.x (2006).

39. Emerson BC, Gillespie RG. Phylogenetic analysis of community assembly and structure over space and time. Trends Ecol. Evol. 23: 619-630. (2008).

40. Losos JB. Phylogenetic niche conservatism, phylogenetic signal and the relationship between phylogenetic relatedness and ecological similarity among species. Ecol. Lett. 11:9951003. https://doi.org/10.1111/j.1461-0248.2008.01229.x (2008).

41. Paganelli $D$, Marchini A, Occhipinti-Ambrogi A. Functional structure of marine benthic assemblages using Biological Traits Analysis (BTA): a study along the Emilia-Romagna coastline (Italy, North-West Adriatic Sea). Estuarine, Coastal and Shelf Science 96: 245256. https://doi.org/10.1016/j.ecss.2011.11.014 (2012). 
42. Escudero A, Valladares F. Trait-based plant ecology: moving towards a unifying species coexistence theory. Oecologia 180:919-922. https://doi.org/10.1007/s00442-016-3578-5 (2016).

43. Klais R, Norros V, Lehtinen S, Tamminen T, Olli K. Community assembly and drivers of phytoplankton functional structure. Functional Ecology 31:760-767. https://doi.org/10.1111/1365-2435.12784 (2017).

44. Lavorel S, Garnier É. Predicting changes in community composition and ecosystem functioning from plant traits: revisiting the Holy Grail. Functional ecology 16(5): 545-556. (2002).

45. Blomberg, S.P., T. Garland JR. Tempo and mode in evolution: phylogenetic inertia, adaptation and comparative methods. J. Evol. Biol. 15:899-910. https://doi.org/10.1046/j.1420-9101.2002.00472.x (2002).

46. Pavoine S, Baguette M, Bonsall MB. Decomposition of trait diversity among the nodes of a phylogenetic tree. Monographs 80:485-507. https://doi.org/ tadpoles with stages ranging from 33 to 39 (sensu Gosner, 1960) (see de Souza Queiroz et al., 2015). (2010).

47. Wiens JJ, Graham CH, Graham H. Niche Conservatism: Integrating Evolution, Ecology, and Conservation Biology. Annu. Rev. Ecol. Syst 36:519539. https://doi.org/10.1146/annurev.ecolsys.36.102803.095431 (2012).

48. Baraloto $\mathrm{C}$. et al. Using functional traits and phylogenetic trees to examine the assembly of tropical tree communities. Journal of Ecology 100:690-701. https://doi.org/10.1111/j.13652745.2012.01966.x (2012).

49. Best RJ, Caulk NC, Stachowicz JJ. Trait vs. phylogenetic diversity as predictors of competition and community composition in herbivorous marine amphipods. Ecology Letters 16:7280. https://doi.org/10.1111/ele.12016 (2013).

50. Cadotte MW, Jonathan Davies T, Peres-Neto PR. Why phylogenies do not always predict ecological differences. Ecological Monographs 87:535-551. https://doi.org/10.1002/ecm.1267 (2017).

51. Jenkins CN, Pimm SL, Joppa LN. Global patterns of terrestrial vertebrate diversity and conservation. Proc. Natl. Acad. Sci. USA 110:602-10. https://doi.org/10.1073/pnas.1302251110 (2013).

52. Segalla MV. Brazilian Amphibians: List of Species. Herpetologia Brasileira, 5: p.34-46. (2016).

53. Dubois A. The nomenclatural status of Hysaplesia, Hylaplesia, Dendrobates and related nomina (Amphibia, Anura), with general comments on zoological nomenclature and its governance, as well as on taxonomic databases and websites. Bionomina 11:148. http://dx.doi.org/10.11646/bionomina.11.1 (2017).

54. Duellman WE, Marion AB, Hedges SB. Phylogenetics, classification, and biogeography of the treefrogs (Amphibia: Anura: Arboranae). Zootaxa, 4104:1109. http://dx.doi.org/10.11646/zootaxa.4104.1.1. (2016).

55. Faivovich J. et al. Systematic Review of the Frog Family Hylidae, With Special Reference To Hylinae: Phylogenetic Analysis and Taxonomic Revision. Bull. Am. Museum Nat. Hist. 294:1240. https://doi.org/10.1206/0003-0090 (2005). 
56. Frost DR. et al. The amphibian tree of life. Bull. Am. Museum Nat. Hist. 1291. http://dx.doi.org/10.5531/sd.sp.13 (2006).

57. Grant T. et al. Phylogenetic systematics of dart-poison frogs and their relatives (Amphibia:Athesphatanura: Dendrobatidae). Am. Museum Nat. Hist. 1: 190. https://doi.org/10.1206/0003-0090 (2006).

58. Pyron RA, Wiens JJ. A large-scale phylogeny of Amphibia including over 2800 species, and a revised classification of extant frogs, salamanders, and caecilians. Mol. Phylogenet. Evol. 61: p.54383. https://doi.org/10.1016/j.ympev.2011.06.012 (2011).

59. Becker CG, Fonseca CR, Haddad CFB, Batista RF, Prado PI. Habitat split and the global decline of amphibians. Science, 318: 1775-1777. (2007).

60. Kozak KH, Wiens JJ. Does niche conservatism promote speciation? A case study in North American salamanders. Evolution 60:2604-21. https://doi.org/10.1554/06-334.1 (2006).

61. Keller A, Rödel M, Linsenmair KE, Grafe TU. The importance of environmental heterogeneity for species diversity and assemblage structure in Bornean stream frogs. J. Anim. Ecol. 78:305314. https://doi.org/10.1111/j.1365-2656.2008.01457.x (2009).

62. Mcdiarmid RW, Altig R. Tadpoles: The Biology of Anuran Larvae R. W. McDiarmid and R. Altig 1st edn., University of Chicago Press, Chicago and London. (1999).

63. Gascon C. Population-and community-level analyses of species occurrences of central Amazonian rainforest tadpoles. Ecology 72:1731-1746. https://doi.org/10.2307/1940972. (1991)

64. Zimmerman B, Simberloff D. An historical interpretation of habitat use by frogs in a Central Amazonian forest. Journal of biogeography 23:27-46. https://doi.org/10.1046/j.13652699.1996.d01-218.x. (1996)

65. Chase JM, Leibold MA. Ecological niches: interspecific interactions. The University of Chicago Press, Chicago. https://doi.org/10.1098/rstb.2010.0034. (2003)

66. Suguio K, Martin L. Formações quaternárias marinhas do litoral paulista e sul fluminense (Quaternary marine formations of the State of São Paulo and southern Rio de Janeiro). In: International Symposium On Coastal evolution in the Quaternary, São Paulo, pp 1-55 (1978).

67. Suguio K, Martin L. The role of neotectonics in the evolution of the Brazilian coast. Rev. Geonomos 4:45-53. (1996).

68. Mcdiarmid RW, Altig R. Tadpoles: The Biology of Anuran Larvae R. W. McDiarmid and R. Altig 1st edn., University of Chicago Press, Chicago and London. (1999).

69. Wells KD. The Ecology and behavior of Amphibians. The University of Chicago Press, Chicago. (2007).

70. Anderson MJ, Ellingsen KE McArdle BH. Multivariate dispersion as a measure of beta diversity. Ecology Letters 9:683-693. https://doi.org/10.1111/j.1461-0248.2006.00926.x (2006).

71. Pavoine S, Vallet J, Dufour AB, Gachet S, Daniel H. On the challenge of treating various types of variables: application for improving the measurement of functional diversity. Oikos 118:391- 
402. https://doi.org/10.1111/j.1600-0706.2008.16668.x (2009).

72. Gower JC. A general coefficient of similarity and some of its properties. Biometrics: 857871. https://doi.org/10.2307/2528823 (1971).

73. Jetz, W., \& Pyron, R. A. The interplay of past diversification and evolutionary isolation with present imperilment across the amphibian tree of life. Nature ecology \& evolution 2 : 850. https://doi.org/10.1038/s41559-018-0515-5 (2018).

74. Rossa-Feres DC, et al.. Amphibians of São Paulo State, Brazil: state-of-art and perspectives. Biota Neotrop. 11:47-66. http://dx.doi.org/10.1590/S1676-06032011000500004 (2011).

75. Gosner K L A simplified table for staging anuran embryos and larvae with notes on identification. Herpetologica, 16: 183-190. https://www.jstor.org/stable/3890061 (1960).

76. de Souza Queiroz C, da Silva FR, Rossa-Feres, DC. The relationship between pond habitat depth and functional tadpole diversity in an agricultural landscape. Royal Society open science 2:150165. http://dx.doi.org/10.1098/rsos.150165. (2015).

77. Strauß A, Reeve E, Randrianiaina RD, Vences M, Glos J. The world's richest tadpole communities show functional redundancy and low functional diversity: ecological data on Madagascar's streamdwelling amphibian larvae. BMC ecology 10: 1-10. https://doi.org/10.1186/1472-6785-10-12 (2010).

78. Both C, Cechin SZ, Melo AS, Hartz SM. What controls tadpole richness and guild composition in ponds in subtropical grasslands? Austral ecology 36:530-536. https://doi.org/10.1111/j.14429993.2010.02183.x (2011).

79. Legendre P, Legendre L. Numerical ecology 3nd edn. Elsevier, (Oxford, 2012).

80. Rao R. Diversity and dissimilarity coefficients: a unified approach. Theor.Popul. Biol. 21: 2443. https://doi.org/10.1016/0040-5809(82)90004-1 (1982).

81. Faith DP. Conservation evaluation and phylogenetic diversity. Biological Conservation, 61:110. https://doi.org/10.1016/0006-3207(92)91201-3 (1992).

82. Kembel SW. Disentangling niche and neutral influences on community assembly: assessing the performance of community phylogenetic structure tests. Ecol. Lett. 12:949960. https://doi.org/10.1111/j.1461-0248.2009.01354.x (2009).

83. Kembel SW. Picante: R tools for integrating phylogenies and ecology. Bioinformatics 26:1463-1464. 1 https://doi.org/0.1093/bioinformatics/btq166 (2010).

84. Swenson NG. Functional and Phylogenetic Ecology in R. Springer-Verlag, New York. https://doi.org/1010.1007/978-1-4614-9542-0 (2014).

85. Podani J. Introduction to the exploration of multivariate biological data. Backhuys Publishers, (Netherlands, 2000)

86. Murtagh F. Multidimensional clustering algorithms. Compstat Lectures, (Vienna, 1985).

87. Laliberte $E$, Legendre P. A distance-based framework for measuring functional diversity from multiple traits. Ecology, 91(1): 299-305. https://doi.org/10.1890/08-2244.1 (2010). 
88. Legendre P. Spatial autocorrelation: trouble or new paradigm? Ecology 74: p.16591673. https://doi.org/10.2307/1939924 (1993).

89. Dormann FC. Methods to account for spatial autocorrelation in the analysis of species distributional data: a review. Ecography 30:609-628. https://doi.org/ 10.1111/j.2007.0906-7590.05171.x (2007).

90. Burnham, KP Multimodel Inference: Understanding AIC and BIC in Model Selection. Sociol. Methods Res. 33:261-304. https://doi.org/10.1177/0049124104268644 (2004).

91. Anderson ADR, Burnham KP, White GC. AIC Model Selection in Overdispersed Capture-Recapture Data. Ecology 75:1780-1793. https://doi.org/10.2307/1939637 (2012).

92. Dray S, Legendre P, Peres-Neto PR. Spatial modelling: a comprehensive framework for principal coordinate analysis of neighbour matrices (PCNM). Ecol. Modell. 196:483-493. https://doi.org/ 10.1016/j.ecolmodel.2006.02.015 (2006).

93. Nally R, Walsh CJ. Hierarchical partitioning public-domain software. Biodiversity and Conservation 13: 659-660. https://doi.org/10.1023/B:BIOC.0000009515.11717.0b (2004).

94. Mac Nally R. Multiple regression and inference in ecology and conservation biology: further comments on identifying important predictor variables. Biodivers. Conserv. 11:13971401. https://doi.org/10.1023/A:1016250716679 (2002).

95. Slingsby JA, Verboom GA. Phylogenetic relatedness limits co-occurrence at fine spatial scales: evidence from the Schoenoid sedges (Cyperaceae: Schoeneae) of the Cape Floristic Region, South Africa. Am. Nat. 168:14-27. https://www.jstor.org/stable/10.1086/505158 (2006)

96. Swenson NG, Enquist BJ, Thompson J, Zimmerman JK. The influence of spatial and size scale on phylogenetic relatedness in tropical forest communities. Ecology 88:1770-

1780. https://doi.org/10.1890/06-1499.1 (2007)

97. de Araújo Martins C. et al. What shapes the phylogenetic structure of anuran communities in a seasonal environment? The influence of determinism at regional scale to stochasticity or antagonistic forces at local scale. PloS one 10(6): e0130075. https://doi.org/10.1371/journal.pone.0130075 (2015).

98. Moura MR, Costa HC, Argôlo AJ, Jetz W. Environmental constraints on the compositional and phylogenetic beta-diversity of tropical forest snake assemblages. Journal of Animal Ecology 86:1192-1204. https://doi.org/10.1111/1365-2656.12699 (2017)

99. do Nascimento ER, Correia I, Ruiz-Esparza JM Gouveia SF Disentangling phylogenetic from nonphylogenetic functional structure of bird assemblages in a tropical dry forest. https://doi.org/10.1111/oik.04910 (2018).

100. Sobral FL, Cianciaruso MV. Functional and phylogenetic structure of forest and savanna bird assemblages across spatial scales. Ecography, 39:533-541. https://doi.org/10.1111/ecog.00903 (2016).

101. Presley SJ. et al. Phylogenetic and functional underdispersion in Neotropical phyllostomid bat communities. Biotropica, 50:135-145. https://doi.org/10.1111/btp.12501 (2018). 
102. Boucek RE, Rehage JS. Climate extremes drive changes in functional community structure. Global change biology, 20(6), 1821-1831. https://doi.org/10.1111/gcb.12574 (2014).

103. Leitão RP. Disentangling the pathways of land use impacts on the functional structure of fish assemblages in Amazon streams. Ecography 41:219-232. https://doi.org/10.1111/ecog.02845 (2018).

104. Paine RT. Food web complexity and species diversity. The American Naturalist, 100? 65-75. (1966)

105. Sih A. Predator and prey lifestyles: an evolutionary and ecological overview. In: Predation: direct and indirect impacts on aquatic communities (Kerfoot WC, Sih A, eds) : University Press of New England, New Hampshire: pp 203-224. (1987).

106. Lima SL, Dill LM. Behavioral decisions made under the risk of predation: a review and prospectus. Can. J. Zool. 68:619-640. (1990).

107. Tollrian R, Harvell CD. The ecology and evolution of inducible defenses, Princeton University Press, New Jersey. (1999).

108. Relyea RA, Werner EE, Mceachran JD. Morphological plasticity in four larval anurans distributed along an environmental gradient. Copeia 2000:178-190. (2000).

109. Relyea RA. Local population differences in phenotypic plasticity: predator-induced changes in wood frog tadpoles. 72:77-93. https://doi.org/10.1890/0012-9615(2002)072[0077:LPDIPP]2.0.C0;2 (2002)a.

110. Relyea RA. Competitor-induced plasticity in tadpoles: consequences, cues, and connections to predator-induced plasticity. Ecol. Monogr. 72: 523-540. https://doi.org/10.1890/00129615(2002)072[0523:CIPITC]2.0.C0;2 (2002)b.

111. Relyea RA. The many faces of predation: how induction, selection, and thinning combine to alter prey phenotypes. Ecology 83:1953-1964. https://doi.org/10.1890/00129658(2002)083[1953:TMFOPH]2.0.C0;2 (2002)c.

112. Morin PJ. Predation, competition, and the composition of larval anuran guilds. Ecol. Monogr. 53: p.119-138. https://doi.org/10.2307/1942491 (1983).

113. Van Buskirk J, Relyea RA. Natural selection for phenotypic plasticity: predator-induced morphological responses in tadpoles. Biol. J. Linn. Soc. 65:301-328. https://doi.org/10.1111/j.10958312.1998.tb01144.x (1998).

114. Rodríguez $\mathrm{C}$. et al. Toxins and pharmacologically active compounds from species of the family Bufonidae (Amphibia, Anura). Journal of ethnopharmacology 198:235254. https://doi.org/10.1016/j.jep.2016.12.021 (2017).

115. Leão-Pires TA, Luiz AM, Sawaya RJ. The complex roles of space and environment in structuring functional, taxonomic and phylogenetic beta diversity of frogs in the Atlantic Forest. PLoS ONE 13(4): e0196066. https://doi.org/10.1371/journal.pone.0196066 (2018).

116. Moss BR. Ecology of freshwaters: man and medium, past to future, 4th edn. John Wiley and Sons. Oxford. (2010). 
117. Waide et al. The relationship between productivity and species richness. Annu. Rev. Ecol. Syst. 30:257-300. https://doi.org/10.1146/annurev.ecolsys.30.1.257 (1999)

118. Skelly DK, Bolden SR, Freidenburg LK. Experimental canopy removal enhances diversity of vernal pond amphibians. Ecological Applications, 24: 340-345. https://doi.org/10.1890/13-1042.1 (2014).

119. Schiesari L Pond canopy cover: a resource gradient for anuran larvae. Freshw. Biol. 51:412423. doi:10.1111/j.1365-2427.2005.01497.x (2006).

120. Gascon C. Population and community-level analyses of species occurrences of central Amazonian rainforest tadpoles. Ecology 72:1731-1746. http://dx.doi.org/10.5531/sd.sp.13 (1991).

121. Moreira LFB, Machado IF, Garcia TV, Maltchik L. Factors influencing anuran distribution in coastal dune wetlands in southern Brazil. Journal of Natural History, 44: 1493-

1507. https://doi.org/10.1080/00222931003632690 (2010).

122. Silva F, Oliveira TL, Gibbs JP, Rossa-Feres DC. An experimental assessment of landscape configuration effects on frog and toad abundance and diversity in tropical agro-savannah landscapes of southeastern Brazil. Landsc. Ecol. 27:87-96. https://doi.org/10.1007/s10980-0119670-7 (2011).

123. Werner EE, Glennemeier KS. Influence of Forest Canopy Cover on the Breeding Pond Distributions of Several Amphibian Species. Copeia: 1-12. https://doi.org/10.2307/1447379 (1999).

124. Provete DB, Gonçalves-Souza T, Garey MV, Martins IA, Rossa-Feres DDC. Broad-scale spatial patterns of canopy cover and pond morphology affect the structure of a Neotropical amphibian metacommunity. Hydrobiologia 734:69-79. https://doi.org/10.1007/s10750-014-1870-0 (2014).

125. Rowland FE, Tuttle SK, González MJ, Vanni MJ. Canopy cover and anurans: nutrients are the most important predictor of growth and development. Canadian Journal of Zoology 94:225232. https://doi.org/10.1139/cjz-2015-0022 (2016).

126. Altig R, McDiarmid RW. Morphological diversity and evolution of egg and clutch structure in amphibians. Herpetological Monographs, 21(1), 1-32. https://doi.org/10.1655/06-005.1 (2007).

127. Kopp KA, Signorelli L, Bastos RP. Distribuição temporal e diversidade de modos reprodutivos de anfíbios anuros no Parque Nacional das Emas e entorno, estado de Goiás, Brasil. (2010).

128. Cardoso AJ, Andrade GV. Distribuição Espacial em Comunidades de Anfíbios (Anura) no Sudeste do Brasil. Rev. Bras. Biol. 49:241-249. (1989).

129. Wassersug RJ, Seibert EA. Behavioral responses of amphibian larvae to variation in dissolved oxygen. Copeia:86-103. (1975).

130. Noland R, Ultsch GR. The roles of temperature and dissolved oxygen in microhabitat selection by the tadpoles of a frog (Rana pipiens) and a toad (Bufo terrestris). Copeia:645-652. (1981).

131. Nie M, Crim JD, Ultsch GR. Dissolved oxygen, temperature, and habitat selection by bullfrog (Rana catesbeiana) tadpoles. Copeia, 153-162. (1999). 
132. Eterovick PC, Barata IM. Distribution of tadpoles within and among Brazilian streams: the influence of predators, habitat size and heterogeneity. Herpetologica, 62:365-

377. https://doi.org/10.1655/0018-0831 (2006).

\section{Table}

Table 1. Stepwise Model Selection based on $\mathrm{AIC}_{\mathrm{C}}$ results for predicting the (a) phylogenetic structure of anurans' communities in coastal plains of Atlantic Forest (* Best explanatory model fitted $\mathrm{R}^{2}=0.58$ ) and (b) functional structure of anurans' communities in coastal plains of Atlantic Forest. (* Best explanatory model fitted $\mathrm{R}^{2}=0.41$ ), predator $=$ presence of potential fish predator, area $=$ pond's surface area, ext_div = external vegetation diversity, int_div $=$ internal vegetation diversity; canopy $=$ canopy cover; $\mathrm{DO}=$ dissolved oxygen; temp $=$ water temperature; conductivity $=$ water conductivity; $\mathrm{pH}=\mathrm{pH}$ value.

(a)

\begin{tabular}{|c|c|c|c|c|c|}
\hline Predictive models & $\begin{array}{l}\text { Model } \\
I D\end{array}$ & $\begin{array}{l}\text { Number of } \\
\text { parameters } \\
\text { (D) }\end{array}$ & $A I C_{C}$ & $\begin{array}{l}\text { Delta } \\
A I C_{C} \\
\left(\Delta_{i}\right)\end{array}$ & $\begin{array}{l}\text { Akaike } \\
\text { weight } \\
\left(\square_{i}\right)\end{array}$ \\
\hline $\begin{array}{l}\text { predator, ext_div, int_div, canopy, } \\
\text { DO and conductivity }\end{array}$ & 5 & 6 & 0.89 & 0.0 & 0.49 \\
\hline $\begin{array}{l}\text { predator, ext_div, int_div, canopy, } \\
\text { DO, temp and conductivity }\end{array}$ & 4 & 7 & 1.92 & 1.03 & 0.29 \\
\hline $\begin{array}{l}\text { predator, ext_div, int_div, canopy, } \\
\text { DO, temp, conductivity and depth }\end{array}$ & 3 & 8 & 3.57 & 2.68 & 0.13 \\
\hline $\begin{array}{l}\text { predator, ext_div, int_div, canopy, } \\
\text { DO, temp, conductivity, area and depth }\end{array}$ & 2 & 9 & 5.42 & 4.53 & 0.05 \\
\hline $\begin{array}{l}\text { predator, ext_div, int_div, canopy, DO, } \mathrm{pH} \text {, } \\
\text { temp, conductivity, area and depth }\end{array}$ & 1 & 10 & 7.42 & 6.53 & 0.01 \\
\hline
\end{tabular}

(b) 


\begin{tabular}{|c|c|c|c|c|c|}
\hline Predictive models & $\begin{array}{l}\text { Model } \\
\text { ID }\end{array}$ & $\begin{array}{l}\text { Number of } \\
\text { parameters () }\end{array}$ & $A I C_{C}$ & $\begin{array}{l}\text { Delta } A I C_{C} \\
\left(\Delta_{i}\right)\end{array}$ & $\begin{array}{l}\text { Akaike } \\
\text { weight }\left(\square_{i}\right)\end{array}$ \\
\hline $\begin{array}{l}\text { predator, ext_div, } \\
\text { canopy, }\end{array}$ & 6 & 5 & 29.9 & 0.00 & 0.48 \\
\hline $\begin{array}{l}\text { DO and area } \\
\text { predator, ext_div, } \\
\text { canopy, DO, } \\
\text { conductivity and area }\end{array}$ & 5 & 6 & 31.1 & 1.11 & 0.27 \\
\hline $\begin{array}{l}\text { predator, ext_div, } \\
\text { canopy, DO, } \\
\text { conductivity and area }\end{array}$ & 4 & 7 & 32.36 & 2.46 & 0.14 \\
\hline $\begin{array}{l}\text { predator, ext_div, } \\
\text { canopy, DO, temp, } \\
\text { conductivity, area and } \\
\text { depth }\end{array}$ & 3 & 8 & 33.83 & 3.92 & 0.06 \\
\hline $\begin{array}{l}\text { predator, ext_div, } \\
\text { canopy, DO, pH, } \\
\text { temp, conductivity, area } \\
\text { and depth }\end{array}$ & 2 & 9 & 35.76 & 5.86 & 0.02 \\
\hline $\begin{array}{l}\text { predator, ext_div, } \\
\text { int_div, canopy, } \\
\text { DO, pH, temp, } \\
\text { conductivity, area and } \\
\text { depth }\end{array}$ & 1 & 10 & 37.69 & 7.79 & .01 \\
\hline
\end{tabular}

Figures 


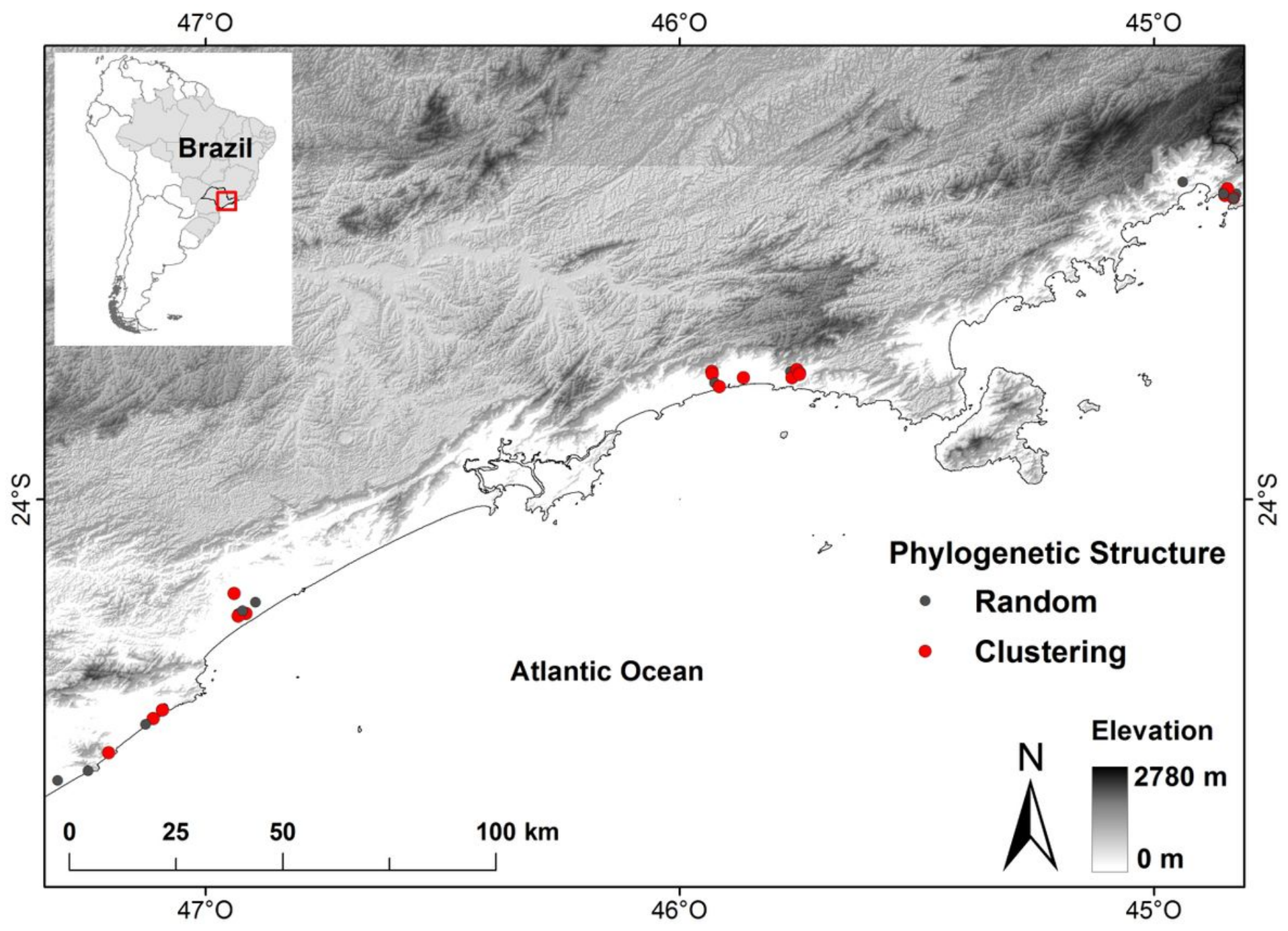

Figure 1

Sampling area in the coastal plains of Atlantic Forest, Southeastern, Brazil. Anurans sampled assemblages are represented by circles. Phylogenetic clustered communities are represented by red circles while phylogenetic randomly communities are represented by grey circles. 


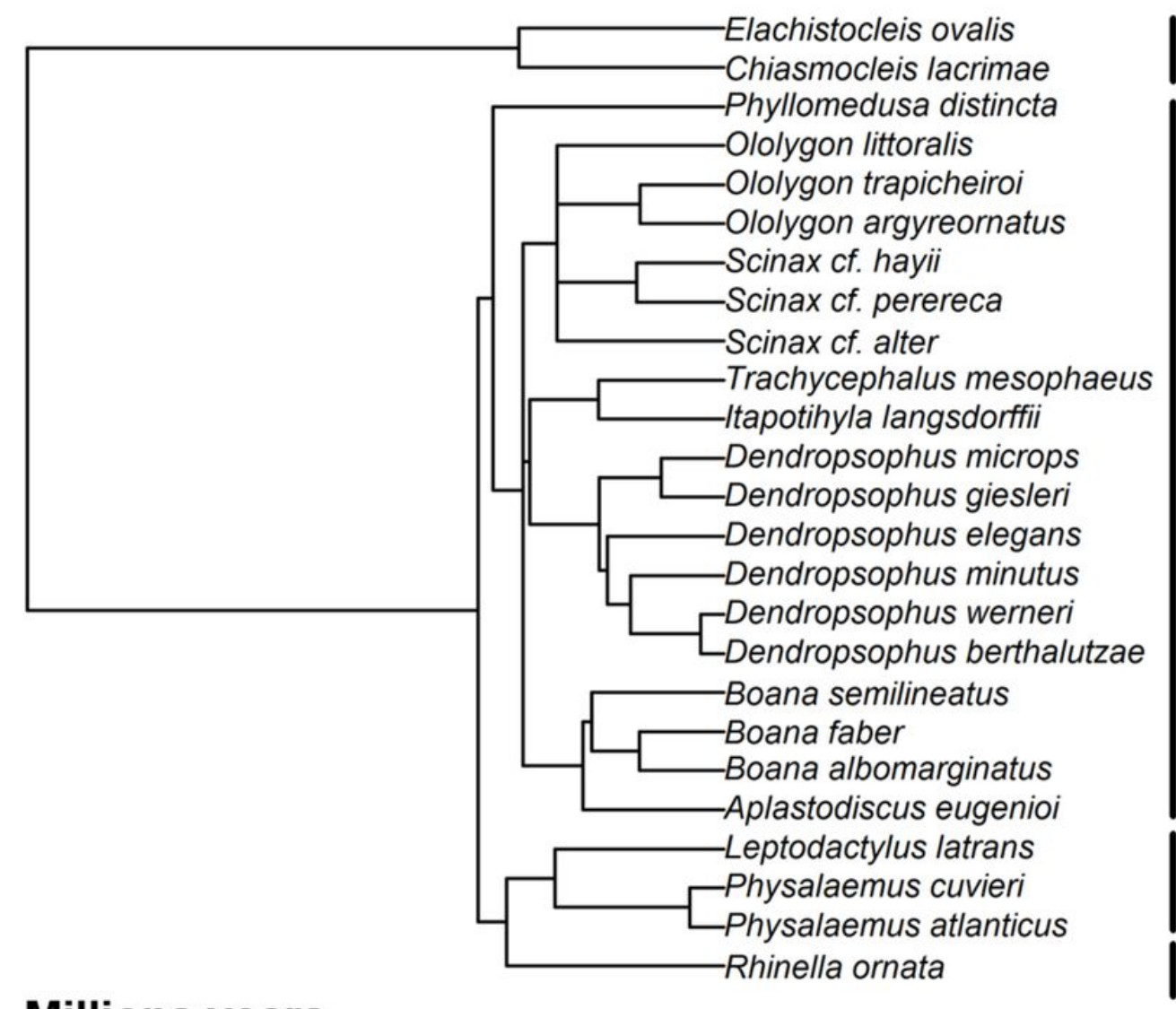

Microhylidae

Hylidae

Leptodactylidae

Bufonidae

\section{Millions years}

Figure 2

Phylogenetic relationships of anuran tadpoles species recorded in the coastal plains of Atlantic Forest, Southeastern, Brazil, based on a phylogenetic hypothesis proposed by Jetz and Pyron (2018). Families are indicated on right. 


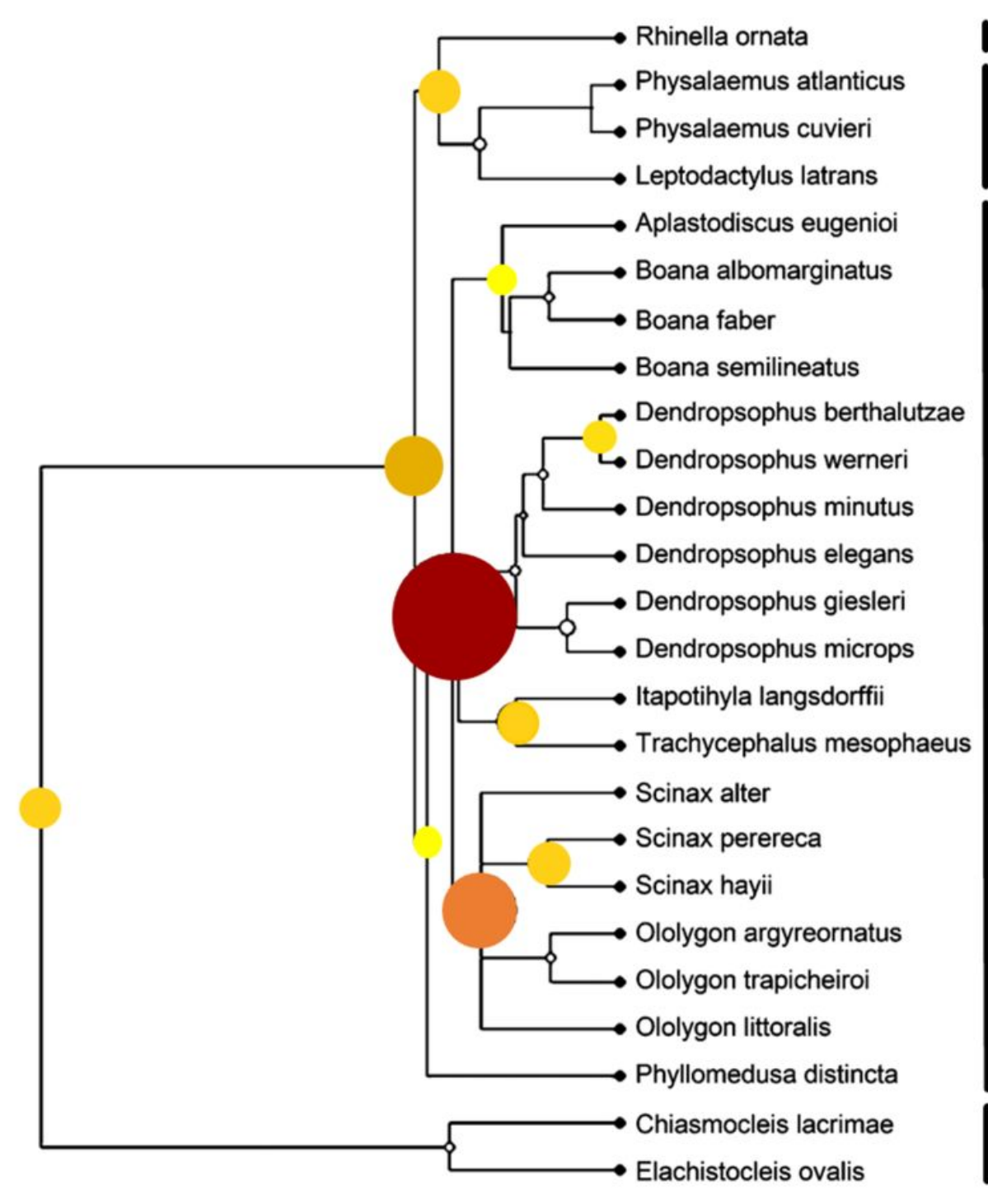

\section{Bufonidae \\ Leptodactylidae}

\section{Hylidae}

\section{Microhylidae}

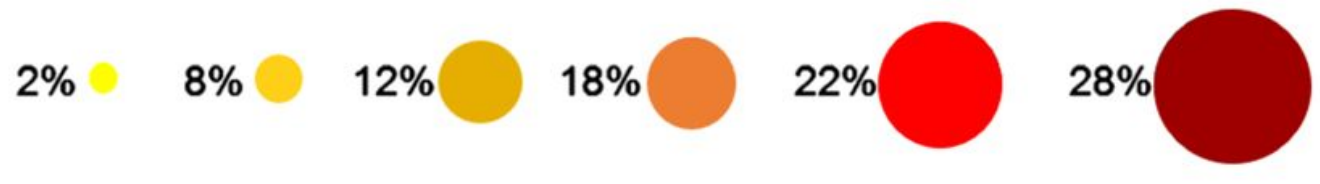

\section{Figure 3}

Decomposition of trait diversity among the nodes of the phylogenetic tree assembled from sampled tadpoles. The circle's size is proportional to contribution (\%) of each node to the total trait diversity. The values next to circles are the percentage of individual contribution to total trait diversity. Families are indicated on right. 

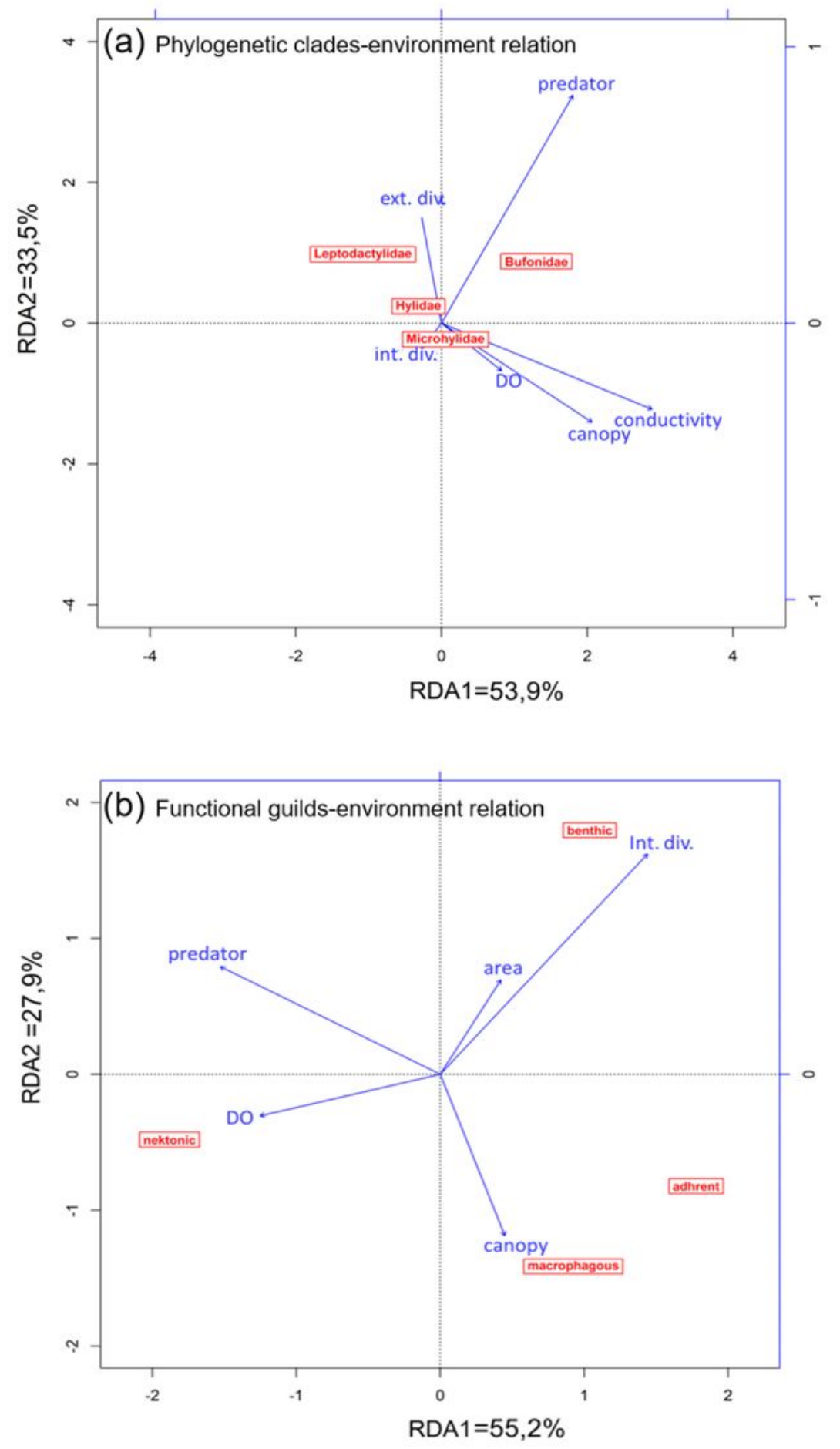

\section{Figure 4}

Redundancy analysis (RDA) biplot based on a phylogenetic clades at the family level and $b$ functional guilds, with environmental factors as explanatory variables. Blue vectors represent environmental variables. Arrow indicates direction of increase in variables from ordination center. Angle between the variables represents their correlations, the smaller the angle, the greater the correlation 

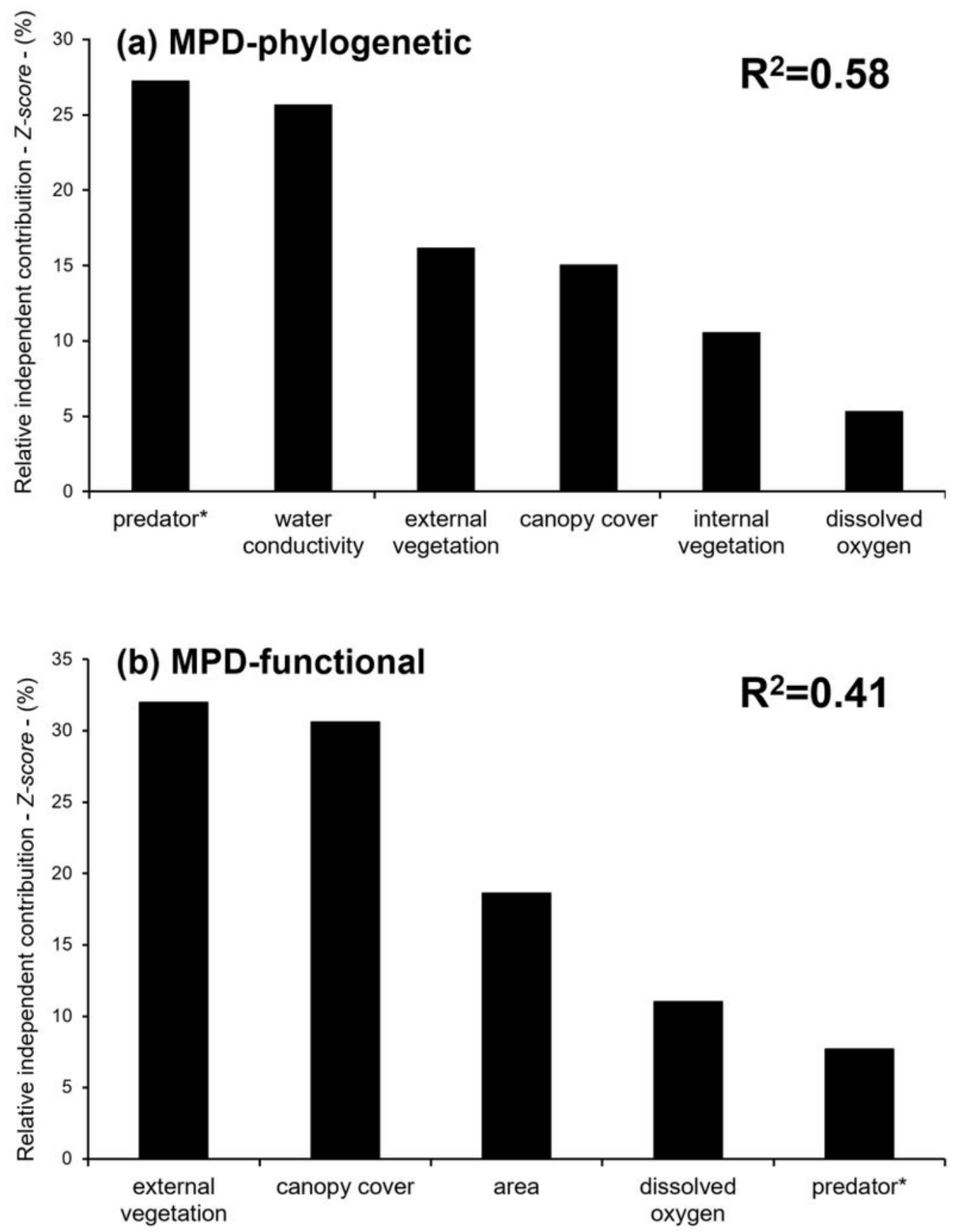

\section{Figure 5}

Hierarchical partitioning of the independent effects of the best environmental drivers, selected by stepwise model selection based on AICc, to the variance of a phylogenetic structure (MPD-phylogenetic) of anuran communities. predator= presence of potential fish predator, external vegetation= external vegetation diversity, internal vegetation= internal vegetation diversity; $b$ functional structure (MPDfunctional) of anuran communities. predator $=$ presence of potential fish predator, area $=$ pond's surface 
area, external vegetation= external vegetation diversity, internal vegetation= internal vegetation diversity; *denotes positive correlation with the response variable.

\section{Supplementary Files}

This is a list of supplementary files associated with this preprint. Click to download.

- SuplementaryInformationSR.pdf.docx 